\title{
Elucidation of Macroeconomic Determinants for Prognosis of Buruli Ulcer
}

\author{
Sudipendra Nath Roy ${ }^{1^{*}}$, Avik Sinha ${ }^{2}$ \\ ${ }^{1}$ Department of Operations Management and Quantitative Techniques, Indian Institute of Management Indore, \\ Indore, India \\ ${ }^{2}$ Accendere Knowledge Management Services, Hyderabad, India \\ Email: *f13sudipendrar@iimidr.ac.in, f11aviks@iimidr.ac.in
}

Received 2 May 2016; accepted 16 July 2016; published 19 July 2016

Copyright (C) 2016 by authors and Scientific Research Publishing Inc.

This work is licensed under the Creative Commons Attribution International License (CC BY).

http://creativecommons.org/licenses/by/4.0/

(c) (i) Open Access

\section{Abstract}

This paper discusses the macroeconomic factors which are responsible for the spread of Buruli Ulcer. As the definitive indicators for the transmission of this neglected tropical disease have not been found yet, therefore, the indicators being found by means of this study can provide significant insights to the health policy makers. This study is carried out for ten African countries and Papua New Guinea for the duration of 2002-2013. Fixed effect panel regression has been employed for the study on the orthogonally transformed dataset. We find that the health policy initiatives have been found to have little or no impact on the Buruli Ulcer prevalence. We also find that access to water from improved sources can reduce the probability of the incidence of this disease.

\section{Keywords}

\section{Neglected Tropical Disease, Africa, Health Policy, Panel Regression}

\section{Introduction}

The number of the most underprivileged people of the world can count more than a billion, and they are the ones, who can easily fall into the poverty trap of disease, conflict, and lack of education. One of such menacing outcomes of poverty trap is neglected tropical disease (NTD) [1]. Currently, at least one billion people are suffering worldwide from NTDs which are mainly tropical infectious ailments, and these are prevalent in poor population of developing and underdeveloped nations. World Health Organization (WHO) has published a list of all such fifteen diseases (http://www.who.int/neglected_diseases/diseases/en/). The list is topped by Buruli Ulcer (BU) which is an infectious skin disease caused by bacteria Mycobacterium ulcerans [2]. This disease is common in

\footnotetext{
*Corresponding author.
} 
poor humid tropical and sub-tropical areas, neglected in terms of research and development focus, and has high impact on mortality and morbidity rates [3]. Sir Albert Cook observed and reported its first incidence in Kampala, Uganda in 1897. Later, in the 1960s, Dodge and Lunn coined the term "Buruli Ulcer", as they referred to skin ulcers from Buruli County (now called Nakasongola District, Uganda). They also reported first large epidemic of Buruli Ulcer. In 1998, WHO recognized Buruli Ulcer as a re-emerging infectious disease in Western and Central African region with significant impact on public health [4]. Just like other neglected tropical diseases, it also has prevalence majorly in poor countries, affecting the bottom billion people and has lesser attraction in terms of public awareness. Unlike tuberculosis and leprosy, its emergence of endemic outbreak is less known to the world and as a comparatively newer ailment prevalent in financially misfortunate population, it easily finds place in the list of Neglected tropical diseases.

Nations, where Buruli Ulcer has emerged as an endemic disease, are facing social-economic, medical, and developmental problems. At least $60 \%$ of the patients have survived with the deformities occurred from the disease [4]. Eventually, stigma and discrimination follow as sequels within community which also disturb not only social life of the patient but also of the household he or she belongs. Moreover, as it is predominantly affecting the children from the age group of 5 - 15 years [2], the social and economic consequences are long term in nature [5]. In fact, if we consider health condition measure like disease adjusted life years (DALY) loss, it is one of the most serious global burden since this chronic life-long disability, impaired childhood development in population ultimately hinders economic development in disenfranchised communities where prevalence of the ailment is higher [6].

Buruli Ulcer is most prevalent in Africa; especially incidence rates are distinguishably higher in West African countries like Benin, Cote d'Ivore, and Ghana. More than 20,000 cases are reported from these regions [7]. Although there are few cases observed in non-African countries, like Australia and Japan, majority of infection outbreak incidences are observed in the Western African region (Figure 1) with increasing rate of incidence [8] [9]. Prevalence of Buruli Ulcer in impecunious African communities confirms its commonality with other NTDs, where poverty and other macro-economic factors play major roles in ailment progression [3]. Two hypotheses on mode of transmission have been suggested by researchers, i.e. 1) spread of infection by contaminated environment (soil, water, vegetation or insect) [10], and 2) bacteria aerosolized from suspensions of tap water [11]. However, till date, precise mode of transmission of Buruli Ulcer remains elusive [8]. As exact factors contributing in ailment prognosis are unknown, it is important to identify other determinants that can contribute to disease prevalence.

Macroeconomic parameters might be associated with Buruli Ulcer, as it is mainly prevalent in poor countries, and it is already established that poverty has a synergistic role to play for aggravating this disease in community

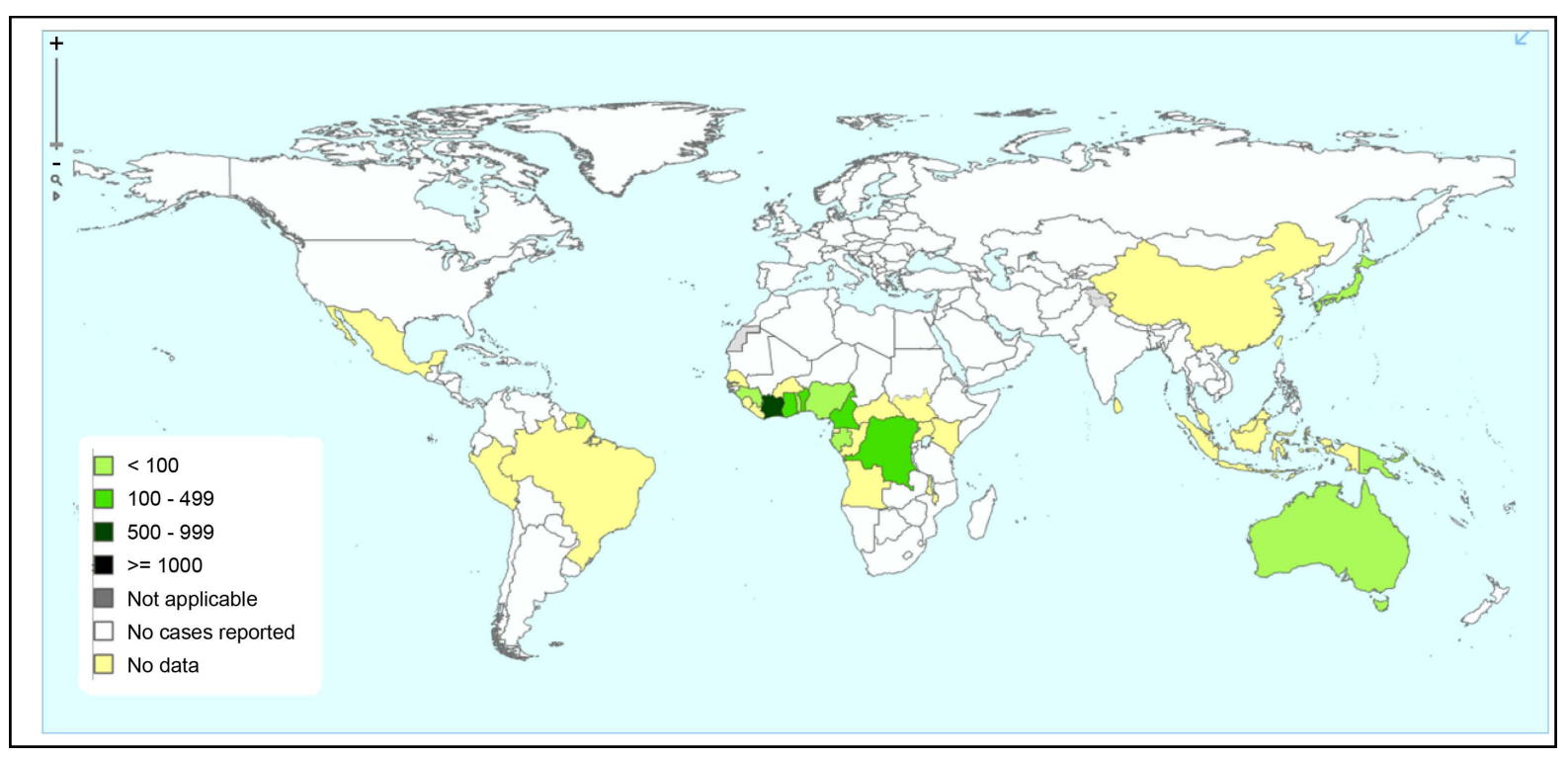

Figure 1. Global scenario of Buruli Ulcer prevalence at present (Source: World Health Organisation, global health observatory data). 
[1]. Till date, there is dearth of literature to identify these macroeconomic factors, which can serve as decision variable for the health policy makers. This paper sheds light in this area by pointing out the macroeconomic indicators which can be responsible for aggravating the spread of this disease in the poor nations.

\section{Literature Review}

Prevention and cure of a tropical disease, like Buruli Ulcer, require considerable attention from public health institutions. As mere intervention of private health enterprises cannot ensure the aforementioned objective, and all the people living in the African countries cannot afford the private healthcare facilities, therefore, they will have to rely on the public health infrastructure. Following the cue of this discussion, this review of literature focuses on the macroeconomic determinants, which can have a possible effect on the Buruli Ulcer incidents, and these determinants are by and large associated with the public health infrastructural initiatives, like national wealth, sanitation, health expenditure, external assistance, etc.

Increase in national wealth generally results into betterment of public health. This fact bolsters the fact that outbreak of communicable diseases, especially NTD incidence has emerged as baleful phenomenon in poor countries. Vulnerable portion of the poor population not only suffers in menacing ailments like Buruli Ulcer but it also dampens economic development of the region [12]. It has been already established that supra-additive combination of poverty, ignorance, poor hygiene, lack of good water supplies and few other social-economic conditions results into enhanced pathogen assault, most prevalently on children [13]. Gross national income (GNI) is a standard measure of national wealth. But, to be more precise, it is necessary to account for the fraction a government spends out of its national income for health expenditure.

Interventions by clinical and public health program are often impractical for a poor country, as neither their health system is capable enough to deliver the interventions, nor wealth reserve can afford complex and necessary strategic disease control programmes. Also, investment decisions should be guided by priority assessment of health infrastructure and disease burden in that region [14]. Per capita total expenditure on health and the contribution in it from the government side are the prime decision variable to capture nation's health to fight back against ailments. Additionally, proportion of government contribution on total expenditure on health must be considered as well.

Apart from government aid, people are also capable to counter illness from their own financial reserve; which is captured by out of pocket expenditure on health. But majority of citizens from a poor developing country may not be able to cater their own medical needs through private or even from any subsidized public healthcare sources. However, this may have a positive impact on diminishing higher prevalence of ailment if affordability is achievable.

Opting neoliberal health policy in a low and middle income nation for controlling a disease has shown negative impact; which justifies governmental steps for the purpose of control and health care programmes for diseases [15]. Government spending on health has to be considered for this reason. On the other hand, insufficient funding for ameliorating the disease by monitoring and infrastructure may necessitate private and external international agencies to contribute in total health expenditure [14].

Buruli Ulcer has been frequently happening in habitants, who live near the water bodies, or perform activities near water like farming. Additionally, although there is no evidence that transmission of disease is from one human to another, education about disease transmission in patients can reduce the incidence. It is practice of better hygiene, which researchers have described as "well-informed" patients living in same geographical region with their improved practice of hygiene, "environment” for disease spread also get changed, which might help to reduce new occurrence of ailments further [16]. Improved water access in rural areas, where Buruli Ulcer is most prevalent and ability to avail better sanitation facilities seems to be prima facie factors in the context of prognosis of Buruli Ulcer.

\section{Data}

Data has been collected for ten African nations and Papua New Guinea for the span of year 2002-2013. In all of these countries, Buruli Ulcer is still reported to be active as per World Health Organization. Data for per capita GNI, percentage of population with access to sanitation facilities, and percentage of rural population with access to improved water source were extracted from World Bank Indicators (http://data.worldbank.org/indicator). Data for per capita expenditure on health, per capita government expenditure on health, total expenditure on health as a percentage of gross domestic product, government expenditure on health as a percentage of total expendi- 
ture on health, private expenditure on health as a percentage of total expenditure on health, government expenditure on health as a percentage of total government expenditure, external resources for health as a percentage of total expenditure on health, out-of-pocket expenditure as a percentage of private expenditure on health, and outof-pocket expenditure as a percentage of total expenditure on health have been taken from World Health Organization database (http://www.who.int/gho/database/en/).

\section{Methodology}

This study employs fixed effect regression method, as the impact of the disease is likely to be same across the countries under consideration (Benin, Cameroon, Congo, Cote d'Ivoire, Democratic Republic of Congo, French Guinea, Ghana, Guinea, Togo, Gabon and Papua New Guinea). In order to achieve the research objective, we have formulated the following regression model:

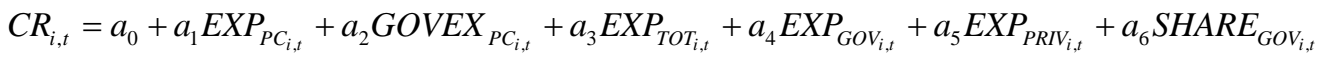

$$
\begin{aligned}
& +a_{7} \text { EXTERNAL }_{i, t}+a_{8} \mathrm{OOP}_{\mathrm{PRIV}_{i, t}}+a_{9} \mathrm{OOP}_{\mathrm{TOT}_{i, t}}+a_{10} \mathrm{GNI}_{P C_{i, t}}+a_{11} \mathrm{SAN}_{i, t}+a_{12} \text { WATER }_{R U R_{i, t}}+\varepsilon_{t}
\end{aligned}
$$

where, $i=1 \cdots \mathrm{N}$ denotes 11 countries and $t=1 \cdots$ T denotes duration of the study, i.e. 2002-2013. CR is the number of cases of Buruli Ulcer reported in that year; EXP_PC is the per capita total expenditure on health expressed in purchasing power parity (PPP) terms; GOVEX_PC is the per capita government expenditure on health expressed in PPP terms; EXP_TOT is the total expenditure on health as a percentage of gross domestic product (GDP); EXP_GOV and EXP_PRIV are government and private expenditures on health expressed as percentages of total expenditure on health respectively; SHARE_GOV is the government expenditure on health as a percentage of total government expenditure; EXTERNAL is the external resources for health as a percentage of total expenditure on health; OOP_PRIV and OOP_TOT are respective out-of-pocket expenditures as percentages of private expenditure and total expenditure on health; GNI_PC is the per capita Gross National Income (GNI) in Purchasing Power Parity (PPP) terms; SAN is depicting access to improved sanitation facilities as the percentage of population using improved sanitation facilities; WATER_RUR is the access to improved water source as the percentage of the population using an improved drinking water source and $\varepsilon$ is error term.

Multicolinearity is a problem with the model. In order to handle this issue, the model have been specified by removing orthogonally transformed independent variables correlating with lower order terms through auxiliary regressions. Once a specification is chosen, the within model has been tested with the original data.

\section{Results and Discussion}

Results of the regression analysis are recorded in Table 1. First, we can see that the access to sanitation facility increases the incidents of Buruli Ulcer. At the same time, we can also find that the access to improved water source reduces the incidents of Buruli Ulcer. Now, these two findings apparently seem to be contradicting, as it is already evident that water vicinity is an intensifying factor for prevalence of the ailment. Our results show that the sanitation facilities are not efficient enough to combat this disease, as the facilities provided by government are not hygienic enough to channelize the excretory products. Initial scrutiny of Buruli Ulcer incidences reports the association with riverside location, or presence of water bodies due to normal social activities, flood, or cultivation purpose [8] [9]. Lack of properly designed sanitation facilities aggravates the incidences of this disease by contaminating these water bodies. Therefore, when the population in these African countries can have the access to improved water source, incidences of this disease fall. This phenomenon bolsters the disease transmission model [17] [18] that suggests the pathogen transferred to terrestrial mammal or human acting as hosts for infection spread. "Mysterious disease" Buruli Ulcer thus may spread from biting of such aquatic hemiptera insect (common name Water strider, Gerris sp.), adult mosquitoes, or other arthropod acting as vector to human [19] [20]. From this segment of the results, it might be said that channeling the excreta, minimizing wastemediated contamination, and carrying out regular pest control can control the growth of the spread of this disease.

When we look at the per capita government expenditure on health, then we can see that it leads to the reduction of the Buruli Ulcer incidents. Apparently this association may seem to be related, but in reality these two events may be disjoint. This is confirmed by the other segments of the results found by us. 
Table 1. Panel regression results.

\begin{tabular}{|c|c|c|c|c|}
\hline \multirow{2}{*}{ Parameters } & \multicolumn{4}{|c|}{ Regression Statistics } \\
\hline & Coefficient & Standard Error & t-statistics & $P>|t|$ \\
\hline$E X P_{P C}$ & $1.1482^{\mathrm{a}}$ & 0.1818351 & 6.31 & 0.000 \\
\hline$G O V E X_{P C}$ & $-0.4064^{\mathrm{a}}$ & 0.0736621 & -5.52 & 0.000 \\
\hline$E X P_{\text {TOT }}$ & - & - & - & - \\
\hline$E X P_{G O V}$ & - & - & - & - \\
\hline$E X P_{P R I V}$ & - & - & - & - \\
\hline$S H A R E_{G O V}$ & $0.1513^{\mathrm{a}}$ & 0.0413051 & 3.66 & 0.000 \\
\hline EXTERNAL & $0.1541^{\mathrm{a}}$ & 0.0479617 & 3.21 & 0.002 \\
\hline$O O P_{P R I V}$ & $-0.2814^{\mathrm{a}}$ & 0.0544922 & -5.16 & 0.000 \\
\hline$O O P_{T O T}$ & 0.0315 & 0.0680186 & 0.46 & 0.644 \\
\hline$G N I_{P C}$ & $0.1540^{\mathrm{a}}$ & 0.0303006 & 5.08 & 0.000 \\
\hline$S A N$ & $0.2040^{\mathrm{a}}$ & 0.0758837 & 2.69 & 0.008 \\
\hline$W A T E R_{R U R}$ & $-0.6979^{\mathrm{a}}$ & 0.0410829 & -16.99 & 0.000 \\
\hline
\end{tabular}

${ }^{\mathrm{a}}$ Significant at $1 \%$ level.

These sanitation issues were being maintained by local or the municipal bodies. Also, government spends an amount of its financial resource in each fiscal year for the health purpose; which may seem a causality wise perfect explanation of the reduced incidence of the disease but we must keep in mind that these events may be disjoint and independent event. Results suggest instead of increased expenditure on health, it is not helping people from the aforementioned African countries. In real scenario, country uses its financial resource for alleviating menace of all ailments rather than targeting a specific disease when it is inchoate stage compared to other contemporary diseases. In Africa other diseases like tuberculosis and Acquired Immune Deficiency Syndrome (AIDS) has enticed so much attention that a neglected tropical disease may seems a lesser important option for consideration; which is also a possible valid explanation for instead of spending financial resources by external resources, incidence of disease was not controlled yet. From the health policy perspective, it is limpid that, financial resources invested are misdirected and targeted wrongly when we consider a neglected tropical disease oriented medical control program or disease intervention initiative. On the other hand, results for private out of pocket expenditure and total out of pocket expenditure has suggested the same as well. Patient who can afford medical treatment on their own has survived to a greater degree due to their ability of spending on the specific diagnosis and treatment of Buruli Ulcer. It also suggests that probably government donation of medicine or medical resource for directly alleviating Buruli Ulcer is less likely to present. A specific health campaign and subsidized medical resource both in terms of personnel, medicine and equipments has to be devoted especially for the people who are comparatively misfortunate than others. This also provides a stanchion to the fact that neglected tropical disease like Buruli Ulcer is truly for the neglected fraction of the people.

It has to be remembered that although it is more prevalent in poor nations in Africa, it is a microbe borne infectious ailment. As a result, now it is showing its existence in developed nations like Australia and Japan in recent years. On the same way, inside disparate African countries, Buruli Ulcer progression remains continuous although infrastructure development is happening over a period. As a result of it, Buruli Ulcer continued to spread from rural to sub-urban to urban areas. It is an ominous sign as the ailment progression is slowly happening instead of development, but till date, it is affecting the less affluent people more. Health policy finalization and decision making steps must be taken by keeping the current status of the disease in mind and the socio-economic indicators that should be addressed for controlling the disease.

\section{Conclusions}

In a nutshell, water vicinity is already established as risk factor for the disease occurrence, from this study, health policy makers can pick up specific points to address prevention and control program like improved water 
treatment with insecticide or other purifier chemicals which are more important than providing a sanitation system with lower sewage efficiency; in fact, that will be detrimental for the population at risk.

Also, it is evident that a neglected tropical disease like Buruli Ulcer is truly affecting the "neglected" population to a greater extent even inside a developing nation where external funding is not directed properly towards an ailment that has a potential to become epidemic in coming days. Clear prognosis pattern can be deciphered from its reach from Africa to Oceania in recent days and from rural to sub-urban population inside affected locality. Health policy makers and public health experts must keep a close watch on every socio-economic and health related parameters responsible for the disease because ignorance towards this "neglected disease" can cost havoc in the near future, and that will not be limited to Africa rather it will spread across the globe.

This study has been focused in the main infection foci i.e. in Africa, from where the ailment emerges and still mostly reported. However, there are data unavailability issues for the entire time period (2002-2013) from some countries like Liberia, Sierra Leone and Nigeria due to various reasons like civil war and socio-political instability. Future works can address these problems by using more data independent techniques like simulation or analytical modeling to delve deeper into the problem.

\section{References}

[1] Hotez, P.J., Fenwick, A., Savioli, L. and Molyneux, D.H. (2009) Rescuing the Bottom Billion through Control of Neglected Tropical Diseases. The Lancet, 373, 1570-1575. http://dx.doi.org/10.1016/S0140-6736(09)60233-6

[2] Wansbrough-Jones, M. and Phillips, R. (2006) Buruli Ulcer: Emerging from Obscurity. The Lancet, 367, 1849-1858. http://dx.doi.org/10.1016/S0140-6736(06)68807-7

[3] Fehr, A., Thürmann, P. and Razum, O. (2011) Expert Delphi Survey on Research and Development into Drugs for Neglected Diseases. BMC Health Services Research, 11, 312. http://dx.doi.org/10.1186/1472-6963-11-312

[4] Dodge, O.G. and Lunn, H. F. (1962) Buruli Ulcer: A Mycobacterial Skin Ulcer in a Uganda Child. Journal of Tropical Medicine and Hygiene, 65, 139-142.

[5] Senior, K. (2009) Buruli Ulcer: Dare We Continue to Ignore It? The Lancet Infectious Diseases, 9, 273. http://dx.doi.org/10.1016/S1473-3099(09)70117-3

[6] Liese, B., Rosenberg, M. and Schratz, A. (2010) Programmes, Partnerships, and Governance for Elimination and Control of Neglected Tropical Diseases. The Lancet, 375, 67-76. http://dx.doi.org/10.1016/S0140-6736(09)61749-9

[7] Johnson, R.C., et al. (2005) Buruli Ulcer Distribution in Benin. Emerging Infectious Diseases, 11, 500-501. http://wwwnc.cdc.gov/eid/article/11/3/pdfs/04-0597.pdf http://dx.doi.org/10.3201/eid1103.040597

[8] Janssens, P., Pattyn, S., Meyers, W. and Portaels, F. (2005) Buruli Ulcer: An Historical Overview with Updating to 2005. Bulletin Des Séances. Académie Royale Des Sciences d'Outre-Mer, 51, 265-299. http://193.190.239.98/handle/10390/1794

[9] World Health Organisation (2004) Buruli Ulcer Disease. Mycobacterium ulcerans Infection: An Overview of Reported Cases Globally. Weekly Epidemiological Record, 79, 193-200. http://www.who.int/wer

[10] Portaels, F., et al. (2001) Mycobacterium ulcerans in Wild Animals. Revue Scientifique et Technique (International Office of Epizootics), 20, 252-264. http://europepmc.org/abstract/med/11288515 http://dx.doi.org/10.20506/rst.20.1.1270

[11] Hayman, J. (1991) Postulated Epidemiology of Mycobacterium ulcerans Infection. International Journal of Epidemiology, 20, 1093-1098. http://ije.oxfordjournals.org/content/20/4/1093.full.pdf+html http://dx.doi.org/10.1093/ije/20.4.1093

[12] Martin, G., Grant, A. and Agostino, M.D. (2012) Global Health Funding and Economic Development. Globalization and Health, 8, 8. http://dx.doi.org/10.1186/1744-8603-8-8

[13] World Health Organisation (1998) World Health Report: Life in the 21st Century. A Vision for All. http://www.who.int/whr/1998/en/

[14] Morrone, A. (2007) Poverty, Health and Development in Dermatology Introduction : A Matter of Urgency. International Journal of Dermatology, 46, 1-9. http://dx.doi.org/10.1111/j.1365-4632.2007.03540.x http://www.skincareforall.org/wp-content/uploads/2012/10/21.-Poverty-Health-and-Development-in-Dermatology.pdf

[15] Unger, J.P., De Paepe, P., Ghilbert, P., Soors, W. and Green, A. (2006) Disintegrated Care : The Achilles Heel of International Health Policies in Low and Middle-Income Countries. International Journal of Integrated Care, 6, 1-13. http://www.ncbi.nlm.nih.gov/pmc/articles/PMC1576566/ $\underline{\text { http://dx.doi.org/10.5334/ijic.156 }}$ 
[16] Agbenorku, P., Agbenorku, M., Amankwa, A., Tuuli, L. and Saunderson, P. (2011) Factors Enhancing the Control of Buruli Ulcer in the Bomfa Communities, Ghana. Transactions of the Royal Society of Tropical Medicine and Hygiene, 105, 459-465. http://dx.doi.org/10.1016/j.trstmh.2011.05.003

[17] Portaels, F., et al. (2010) Family Relationship, Water Contact and Occurrence of Buruli Ulcer in Benin. PLoS Neglected Tropical Diseases, 4, e746. http://dx.doi.org/10.1371/journal.pntd.0000746

[18] Fyfe, J.A.M., et al. (2010) A Major Role for Mammals in the Ecology of Mycobacterium ulcerans. PLoS Neglected Tropical Diseases, 4, e791. http://dx.doi.org/10.1371/journal.pntd.0000791

[19] Merritt, R.W., Walker, E.D., Small, P.L., Wallace, J.R., Johnson, P.D., Benbow, M.E. and Boakye, D.A. (2010) Ecology and Transmission of Buruli Ulcer Disease: A Systematic Review. PLoS Neglected Tropical Diseases, 4, e911. http://dx.doi.org/10.1371/journal.pntd.0000911

[20] Portaels, F., et al. (2008) First Cultivation and Characterization of Mycobacterium ulcerans from the Environment. PLoS Neglected Tropical Diseases, 2, e178. http://dx.doi.org/10.1371/journal.pntd.0000178

\section{Submit or recommend next manuscript to SCIRP and we will provide best service for you:}

Accepting pre-submission inquiries through Email, Facebook, LinkedIn, Twitter, etc. A wide selection of journals (inclusive of 9 subjects, more than 200 journals)

Providing 24-hour high-quality service

User-friendly online submission system

Fair and swift peer-review system

Efficient typesetting and proofreading procedure

Display of the result of downloads and visits, as well as the number of cited articles

Maximum dissemination of your research work

Submit your manuscript at: http://papersubmission.scirp.org/ 